DIGITALCOMMONS $@$ WAYNESTATE-
Clinical Research in Practice: The Journal of Team Hippocrates

\title{
Clinical Decision Science emphasizes unique social context in a way that Evidence-Based Medicine does not
}

\author{
Karen Weaver MD \\ Beaumont Hospital Wayne Family Medicine Residency, karen.weaver@beaumont.org \\ Michelle Diebold MD \\ Beaumont Hospital Family Medicine Residency, Michelle.Diebold@beaumont.org \\ Zeinab Rizk MD \\ Beaumont Hospital Family Medicine Residency, Zeinab.Rizk@beaumont.org \\ Ghada Mustapha MD \\ Beaumont Hospital Family Medicine Residency, Ghada.Mustapha@beaumont.org \\ Wafa Algahmi MD \\ Beaumont Hospital Family Medicine Residency, Wafa.Algahmi@beaumont.org
}

See next page for additional authors

Follow this and additional works at: https://digitalcommons.wayne.edu/crp

Part of the Medical Education Commons

\section{Recommended Citation \\ WEAVER K, DIEBOLD M, RIZK Z, MUSTAPHA G, ALGAHMI W, RIVKIN A, YEE N, MEZA JP. Clinical Decision Science emphasizes unique social context in a way that Evidence-Based Medicine does not. Clin. Res. Prac. Apr 22 2020;6(1):eP2384. https://doi.org/10.22237/crp/1586477100}

This Original Research is brought to you for free and open access by the Open Access Journals at DigitalCommons@WayneState. It has been accepted for inclusion in Clinical Research in Practice: The Journal of Team Hippocrates by an authorized editor of DigitalCommons@WayneState. 


\section{Clinical Decision Science emphasizes unique social context in a way that Evidence-Based Medicine does not}

\section{Erratum}

2020.04.23: Appendix A has been updated to accurately reflect the list of Social determinants of health used in the original study. - JNF

\section{Authors}

Karen Weaver MD, Michelle Diebold MD, Zeinab Rizk MD, Ghada Mustapha MD, Wafa Algahmi MD, Aaron Rivkin MD, Nicholus Yee MD, and James Peter Meza 


\title{
ORIGINAL RESEARCH:
}

\section{Clinical Decision Science emphasizes unique social context in a way that Evidence-Based Medicine does not}

KAREN WEAVER, M.D., Beaumont Hospital Wayne Family Medicine Residency, karen.weaver@beaumont.org MICHELLE DIEBOLD, M.D., Beaumont Hospital Family Medicine Residency, michelle.diebold@beaumont.org ZEINAB RIZK, M.D., Beaumont Hospital Family Medicine Residency, zeinab.rizk@beaumont.org GHADA MUSTAPHA, M.D., Beaumont Hospital Family Medicine Residency, ghada.mustapha@beaumont.org WAFA ALGAHMI, M.D., Beaumont Hospital Family Medicine Residency, wafa.algahmi@beaumont.org AARON RIVKIN, M.D., Beaumont Hospital Wayne Family Medicine Residency, aaron.rivkin@beaumont.org NICHOLUS YEE, M.D., Beaumont Hospital Family Medicine Residency, nicholus.yee@beaumont.org JAMES PETER MEZA, Beaumont Hospital Wayne Family Medicine Residency, imeza@med.wayne.edu

\begin{abstract}
INTRODUCTION: The goal of evidence-based medicine includes the integration of clinical experience and patient values with research evidence. We introduce clinical decision science, a new framework that includes patient social context to demonstrate this integration, which has been absent from evidence-based medicine sources. METHODS: This is an observational study comparing published articles within the domains of clinical decision science and evidence-based medicine. In a standardized manner, investigators identified and counted instances of social interaction within the publications. RESULTS: Publications of Clinical Decision Science had a higher number of markers of social interaction per paper and greater proportion of papers that included any markers of social interaction compared to publications in the Evidence-based medicine domain. DISCUSSION: We identified a framework that allows exploration of a new scientific domain that includes both research evidence and individual patient social context.
\end{abstract}

Keywords: $\quad$ Evidence-Based Medicine, Clinical Decision Science

\section{Introduction}

The introduction of evidence-based medicine (EBM) in the early 1990's has fundamentally changed the process by which physicians and patients decide their next steps in patient care. Evidence-based medicine has sought to bring a more rigorous and scientific approach to both the development of guidelines and policies, as well as clinical decisions in the care of individual patients. ${ }^{-}$Early on, there was recognition that rigor, science, and evidence were necessary, but not sufficient, for optimal decision making. Evidencebased medicine needed to "[integrate] clinical experience and patient values with the best available research information." $\underline{2}$ While individual physicians may achieve this lofty goal, we can find no description of this process in the medical literature. There is no user's manual, no formal teaching, and no defined skillset. We rely on physicians to develop this ability on their own. Once they escape the confines of post-graduate training, most physicians will be left with only minimal and infrequent guidance and even less feedback. We have no evidence that EBM has achieved rigor and application of science to individual decision making in clinical settings.

The authors practice at the Beaumont Family Medicine Residency. JAMES PETER MEZA is the faculty editor and NICHOLUS YEE the managing editor of this journal. 
WEAVER K, DIEBOLD M, RIZK Z, MUSTAPHA G, ALGAHMI W, RIVKIN A, YEE N, MEZA JP. Clinical Decision Science emphasizes unique social context in a way that Evidence-Based Medicine does not. Clin. Res.

Prac. Apr 22 2020;6(1):eP2384. https://doi.org/10.22237/crp/1586477100
Clinical Research in Practice The Journal of Team Hippocrates

VOL 6 ISS 1 / eP2384 / APRIL 22, 2020 https://doi.org/10.22237/crp/1586477100

Individual patient care, by definition, includes a patient within a unique social context. This social context is the environment in which the research evidence must be applied. Haynes, Devereaux, and Guyatt, wrote "Evidence does not make decisions, people do." 3 Research studies are done on populations, but physicians take care of individuals.

Evidence-Based Medicine should bring together the current research, clinical experience, and patient agency when making treatment determinations. ${ }^{2}, 4$ However, EBM publications rarely demonstrate how to perform this integration. We believe that the social context of the patient is the missing framework to accomplish this goal. Yet, social context is absent from existing medical literature and EBM databases. Clinical Research in Practice: The Journal of Team Hippocrates (CRP-JTH) presents case reports that use social context to demonstrate the implementation of clinical research in the care of an individual patient. The relationship between evidence and social context of an individual patient is what we call Clinical Decision Science.

We compared these published case reports of applied evidence to typical EBM publications. The goal of this project is to demonstrate the difference between the scholarly domains of clinical decision science and standard formats of what is known as evidence-based medicine.

\section{Methods}

This was an observational study of published works in the domains of clinical decision science versus evidence-based medicine. This study was determined to be non-human research by the IRB at Beaumont Health. We compared recent publications from CRP-JTH $(n=30)$ to a range of publications sampled from prominent EBM sources $(n=41)$. Publications included UpToDate, Dynamed, Essential Evidence Plus, American Family Physician, American College of Physicians Journal Club, Family Physicians Inquiries Network, Primary Care Medical Abstracts, Broome Docs, and the American Family Physician Podcast. We created a glossary/codebook for the following markers of social interaction: conversations, institutional relationships, emotions, social determinants of health (SDH), patient values / preferences, and family / personal relationships (supplemental material, Appendix A).

Prior to data collection, the investigators met as a group to train and standardize data collection using the codebook. A draft of the codebook was given to the group and discussed in detail, including any clarifying questions or concerns being addressed by the investigators. A training journal article from Clinical Research in Practice: The Journal of Team Hippocrates (CRP-JTH) was then distributed and reviewed by each investigator individually. The team then reconvened and read through the article as a group and discussed similarities and differences in their coding until a consensus was reached. The codebook was then revised to reflect this consensus. For example, the category "behavior" was removed, as the investigation team thought it was too broadly defined, and redundant with other categories of social context. Further, the group listened to several podcast episodes and coded each individually. Similar to the journal article, the group then reconvened and discussed similarities and differences of how they graded each podcast until a consensus was achieved, and the codebook similarly revised. The final codebook is included in the supplemental material as Appendix A.

In the domain of clinical decision science, 30 sequential, most recently published articles available at the time were taken from $C R P$ JTH, each published between August 2018 and September 2019. Thirty articles were used based on a guestimate for the power calculation, given an estimated 0.5 prevalence of recorded social markers in EBM compared to 2.0 in $C R P$-JTH. Representing the domain of evidence-based medicine, 31 total articles were randomly chosen from various EBM databases (indexed EBM aggregators) and publications. Up to 6 contiguous pages were taken from each article, starting at a random page number. These randomly selected articles were taken from DynaMed ( $n=5$ articles), Essential Evidence Plus ( $n=5)$, UpToDate ( $n=6)$, Family Physician Inquiries Network $(n=8)$, American Family Physician $(n=4)$ and American College of Physicians Journal Club ( $n=4)$. Each article was assigned to two investigators to code separately and independently, using the codebook. These investigators were non-contributors and non-readers of CRP-JTH. Different colored highlighters were used to indicate text that described each descriptor of social context in the codebook.

Another EBM format exists that we thought it important to compare-podcasts. Podcasts tend to be informal discussions between clinicians and might have a greater possibility for describing how evidence is used in clinical care. So, 10 podcasts were sampled as well. Random single segments were selected from various podcast programs, with each segment having a duration of about 2-3 minutes. Sampled podcasts include American Family Physician Podcast $(n=4)$, Broome Docs $(n=3)$ and Primary Care Medical Abstracts $(\mathrm{n}=3)$. Investigators met together to listen to each podcast simultaneously, but each investigator coded the podcast 
WEAVER K, DIEBOLD M, RIZK Z, MUSTAPHA G, ALGAHMI W, RIVKIN A, YEE N, MEZA JP. Clinical Decision Science emphasizes unique social context in a way that Evidence-Based Medicine does not. Clin. Res.

Prac. Apr 22 2020;6(1):eP2384. https://doi.org/10.22237/crp/1586477100
Clinical Research in Practice The Journal of Team Hippocrates

VOL 6 ISS 1 / eP2384 / APRIL 22, 2020 https://doi.org/10.22237/crp/1586477100

separately and independently. Investigators used a common abstraction form to take rough notes on phrases that indicated social context.

The duplicate coding of each case was reviewed and compared to each other. Disagreements between coders were resolved by consensus of two authors (JM, NY), both of whom are familiar with the two domains and the formats reviewed and coded. The total number of instances of each social indicator was collected and recorded for each individual article and podcast. The total number of instances of social context were aggregated for CRP-JTH, EBM print articles, and EBM podcasts.

\section{Results}

A total of 71 cases were coded (CRP-JTH $n=30$, EBM print articles $n=31$, EBM podcasts $n=10)$. For one EBM print article, consensus could not be reached and this case was not included in analysis. We compared the average social markers per publication in each group, which revealed 4.7 per CRP-JTH publication, 0.5 per EBM print article and 0.2 per EBM podcast ( $<<0.00001$, Kruskal-Wallis). Data for individual social marker categories is available in Figure 1. These data highlight that the two groups were most similar in reporting "Institutional Relationships" and had a wide discrepancy of frequency in the other.

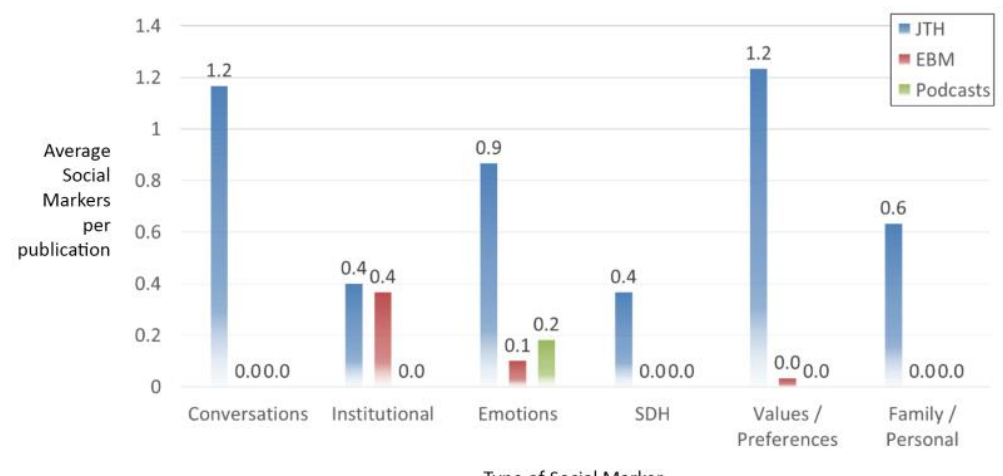

Type of Social Marker

Figure 1. Average Social Markers per Publication

We also analyzed the percentage of cases in each domain containing a marker of social context. Results are demonstrated in Figure 2. These data highlight that social information comes to clinicians most often in the form of conversations and patient values or preferences. Emotions and family or personal information are also important sources of social context.

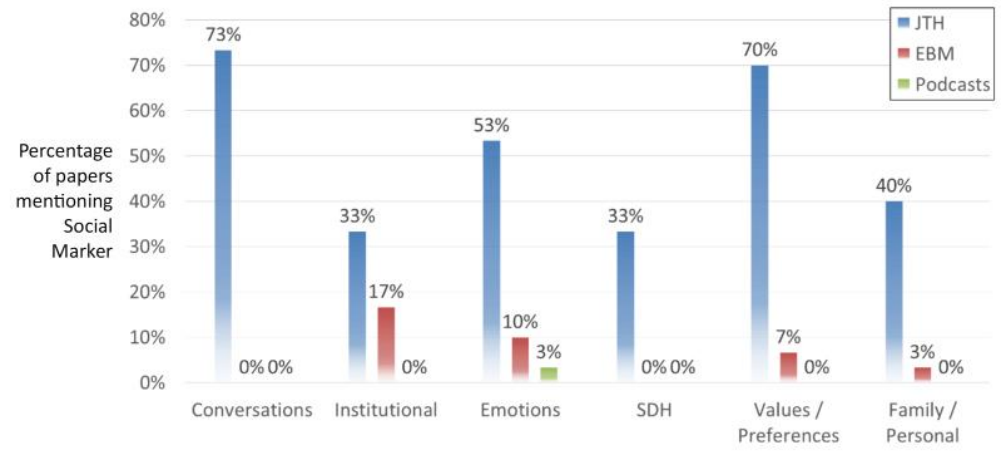

Type of Social Marker

Figure 2. Percentage of publications with Social Markers by type of Social Marker 
WEAVER K, DIEBOLD M, RIZK Z, MUSTAPHA G, ALGAHMI W, RIVKIN A, YEE N, MEZA JP. Clinical Decision Science emphasizes unique social context in a way that Evidence-Based Medicine does not. Clin. Res.

Prac. Apr 22 2020;6(1):eP2384. https://doi.org/10.22237/crp/1586477100
Clinical Research in Practice The Journal of Team Hippocrates

VOL 6 ISS 1 / eP2384 / APRIL 22, 2020 https://doi.org/10.22237/crp/1586477100

Within the group of EBM podcasts, only one case contained any social markers. This was a podcast in which the discussants mentioned their own emotions, not the emotions of patients. Amongst the EBM print articles, the majority of markers of social markers were in the category of institutional relationships. These were often references to medical societies that made recommendations for patient care.

\section{Results}

We were able to demonstrate a difference between the scholarly domains of clinical decision science and evidence-based medicine. Articles in clinical decision science group include a markedly higher attention to the social context of an individual patient. Although this result is to be expected, the most significant finding highlights that an actual difference exists between these two scholarly domains.

The Evidence-Based Medicine Working Group at McMaster University introduced medicine to EBM5, and its development improved the practice of medicine. We have come to expect a more scientific approach to the guidelines and protocols which guide our medical practices. However, that rigorous scientific approach has not been applied to individual patient decisions.

Although the original intent of EBM was to integrate clinical experience, patient values, and research information, this was never accomplished in the research literature or EBM databases and aggregators. Clinical decision science is a scholarly domain that will apply clinical research within a doctor-patient relationship that is shaped by unique social context.

\section{References}

1. Eddy D. Reflections on science, judgment, and value in evidence-based decision making: a conversation with David Eddy by Sean R. Tunis. Health Aff (Millwood). 2007;26(4):500-515. https://doi.org/10.1377/hlthaff.26.4.w500

2. Sackett DL, Rosenberg WM, Gray JA, Haynes RB, Richardson WS. Evidence based medicine: what it is and what it isn't. BMJ. 1996;312(7023):71-72. https://doi.org/10.1136/bmj.312.7023.71

3. Haynes RB, Devereaux PJ, Guyatt GH. Physicians' and patients' choices in evidence based practice. BMJ. 2002;324(7350):1350. https://doi.org/10.1136/bmj.324.7350.1350

4. Masic I, Miokovic M, Muhamedagic B. Evidence based medicine - new approaches and challenges. Acta Inform Med. 2008;16(4):219-225. https://doi.org/10.5455/aim.2008.16.219-225

5. Evidence-Based Medicine Working G. Evidence-based medicine. A new approach to teaching the practice of medicine. JAMA. 1992;268(17):2420-2425. https://doi.org/10.1001/jama.268.17.2420 


\section{Appendix A: Code Book}

\section{Implementing Clinical Research In Practice - Code Book}

While reading or listening to evidence-based medicine content, please denote when the following examples of social markers are mentioned. Sentences can be DOUBLE CODED, with two social markers:

\begin{tabular}{|c|c|c|c|}
\hline & \\
\hline & Description & Examples & Counterexamples \\
\hline $\begin{array}{l}\text { Conversation } \\
\text { (highlight yellow) }\end{array}$ & $\begin{array}{l}\text { - Verbal information transfer } \\
\text { between humans } \\
\text { - At least one participant should be } \\
\text { identifiable }\end{array}$ & $\begin{array}{l}\text { - "The patient told me 'my pain } \\
\text { is severe.'" (direct quotations) } \\
\text { - Indirect quotations / } \\
\text { paraphrasing }\end{array}$ & $\begin{array}{l}\text { - "The patient's pain was severe." } \\
\text { - "The pain radiated to his leg." } \\
\text { (medical data) }\end{array}$ \\
\hline $\begin{array}{l}\text { Institutional relationships } \\
\text { (highlight pink) }\end{array}$ & \begin{tabular}{|l} 
- References to \\
government/hospital rules, policies \\
and constraints \\
- Contractual arrangements that \\
provide privileges or restrictions, \\
e.g. insurance \\
- Interaction between distinctly \\
identifiable groups of people \\
- Excludes family units \\
- Must be able to identify an \\
individual or organization
\end{tabular} & $\begin{array}{l}\text { - "hospital policy says that all } \\
\text { such patients must be in } \\
\text { isolation" } \\
\text { - "Insurance would not cover } \\
\text { the prescribed two-wheeled } \\
\text { walker" } \\
\text { - "Infectious disease disagreed } \\
\text { with pulmonology and wanted } \\
\text { to use ceftraoline" }\end{array}$ & $\begin{array}{l}\text { - "these types of patients are } \\
\text { typically treated as outpatients." } \\
\text { - "the patient did not have a } \\
\text { pharmacy close to his home." } \\
\text { (This would be a social } \\
\text { determinant of health) } \\
\text { - "there is no consensus on how } \\
\text { to treat this disease" }\end{array}$ \\
\hline $\begin{array}{l}\text { Emotions } \\
\text { (highlight green) }\end{array}$ & $\begin{array}{l}\text { - Socially engaged cognitions in the } \\
\text { affective domain } \\
\text { - Expression of patient emotion } \\
\text { - Description of expressed or } \\
\text { inferred emotions. }\end{array}$ & $\begin{array}{l}\text { "The patient was upset to } \\
\text { learn they would have to stay } \\
\text { two more days." }\end{array}$ & $\begin{array}{l}\text { "The patient thought it was } \\
\text { unreasonable to stay two more } \\
\text { days." (This would indicate a } \\
\text { preference rather than an } \\
\text { emotion) }\end{array}$ \\
\hline $\begin{array}{l}\text { Social determinants of health } \\
\text { (underline black) }\end{array}$ & $\begin{array}{l}\text { - See below } \\
\text { - Should apply to an identifiable } \\
\text { patient }\end{array}$ & & \\
\hline $\begin{array}{l}\text { Values / Preferences / Ethical } \\
\text { concerns } \\
\text { (underline red) }\end{array}$ & $\begin{array}{l}\text { - Expression of individual or social } \\
\text { values or preferences } \\
\text { - Dealing with moral issues }\end{array}$ & $\begin{array}{l}\text { "The patient wanted to return } \\
\text { to work as soon as possible." }\end{array}$ & \\
\hline $\begin{array}{l}\text { Family and personal } \\
\text { relationships } \\
\text { (highlight blue) } \\
\end{array}$ & $\begin{array}{l}\text { - Descriptions of familial or close } \\
\text { personal relationships }\end{array}$ & $\begin{array}{l}\text { "Joanie has } 7 \text { daughters who } \\
\text { worry she can't care for } \\
\text { herself." }\end{array}$ & \\
\hline
\end{tabular}

Social determinants of health (WHO): 1) Availability of resources to meet daily needs (e.g., safe housing and local food markets); 2) Access to educational, economic, and job opportunities; 3) Access to health care services; 4) Quality of education and job training; 5) Availability of community-based resources in support of community living and opportunities for recreational and leisure-time activities; 6) Transportation options; 7) Public safety; 8) Social support; 9) Social norms and attitudes (e.g., discrimination, racism, and distrust of government); 10) Exposure to crime, violence, and social disorder (e.g., presence of trash and lack of cooperation in a community); 11) Socioeconomic conditions (e.g., concentrated poverty and the stressful conditions that accompany it); 12) Residential segregation; 13) Language/Literacy; 14) Access to mass media and emerging technologies (e.g., cell phones, the Internet, and social media); 15) Culture; (https://www.healthypeople.gov/2020/topics-objectives/topic/social-determinants-of-health) 